\title{
Community structure of marine bacterioplankton: patterns, networks, and relationships to function
}

\author{
Jed A. Fuhrman*, Joshua A. Steele \\ Department of Biological Sciences and Wrigley Institute for Environmental Studies, University of Southern California, \\ Los Angeles, California 90089-0371, USA
}

\begin{abstract}
Major challenges in marine microbial ecology include determining patterns of community structure and structure-function relationships. Progress has occurred by a combination of molecular and classical techniques. An example for this is work on the marine Crenarchaeota, extremely abundant organisms that we now think play important roles both as autotrophic ammonium oxidizers and as heterotrophs. Another involves the recently discovered Proteorhodopsins, pigments that are potentially important in solar energy capture, yet often do not seem to confer a clear growth benefit to organisms that possess them. Proteorhodopsins occur in numerous phylogenetic groups and may have multiple roles, complicating the linking of these proteins to a well-defined function. Community fingerprinting is a powerful tool for examining community structure and for examining spatial and temporal distribution patterns. Using fingerprinting, we found that ocean communities tend to occur in patches with horizontal dimensions of several $\mathrm{km}$, while samples $10 \mathrm{~s}$ of $\mathrm{km}$ or more apart can be quite different. Temporal analyses such as the San Pedro Ocean Time Series (SPOT) show that near-surface communities are somewhat similar from month to month, then change significantly over several months, and finally return to a similar community annually. Near-surface communities can also be predicted from environmental parameters like temperature, salinity, nutrients, and chlorophyll. Time series data show co-occurrence of organisms (resembling a succession of communities) under particular conditions, or conversely can show which organisms are significantly negatively correlated, indicative perhaps of competition, resource partitioning, or allelopathy. These relationships are visualized here as mathematical interaction networks to map out the 'niche space' of microbial taxa and their correlations, displaying complex ecological interactions. Observations indicate that ecological relatedness does not necessarily closely follow phylogenetic relatedness.
\end{abstract}

KEY WORDS: Bacteria $\cdot$ Archaea $\cdot$ ARISA $\cdot$ Proteorhodopsin $\cdot$ Patchiness $\cdot$ Time series $\cdot$ Networks Resale or republication not permitted without written consent of the publisher

\section{INTRODUCTION}

About 2 decades ago, Olsen et al. (1986) and Pace et al. (1986) introduced the concept of studying the composition of natural microbial communities by sequencing genes cloned directly from biomass, rather than cultures. This started the molecular revolution in microbial ecology, leading to the discovery of previously unknown groups of microorganisms and information about where they live. We can now accurately identitify organisms that were previously considered little dots in the microscope, and say how they are distributed in space and time. Yet one of the biggest chal- lenges is still to determine not only what organisms are present, but what each particular kind of organism is doing and how it interacts and fits into the functioning of the ecosystem. In a sense, we are asking about the natural history of the various microbes, analogous to the intuitive understanding that people have had with animals and plants for millennia, by simply observing what these organisms were doing in nature. With microbes it is, of course, not so simple. Yet this basic understanding is the first step in creating conceptual and predictive models of how the system works as a whole, broken down to include the constituent microorganisms. Linking community structure with 
ecological function is therefore an important, but elusive goal. This review summarizes key approaches, successes, and ongoing challenges in this field. It includes studies that address the problem directly, by linking particular functions to particular organisms, and indirectly, by examining the statistical relationships among organisms and environmental parameters measured over various spatial and temporal scales. Both approaches have their advantages, and statistical investigations even present the possibility of revealing the network of microbial relationships within marine ecosystems. To examine the direct links, 2 case studies were used: one focusing on the functions of a recently discovered group of organisms, the marine Crenarchaea, and the other focusing on a newly discovered protein, proteorhodopsin, which has the potential to significantly impact energy budgets in marine environments.

\section{CASE STUDY 1: MARINE ARCHAEA IN THE NITROGEN CYCLE}

In the 1970s, Woese \& Fox (1977) and Woese et al. (1978) made the startling discovery that a group of organisms originally called 'Archaebacteria' (later renamed Archaea) are fundamentally different from Bacteria, both genetically and physiologically. At that time, all known Archaea were 'extremophiles', living only in places like hot springs (extreme thermoacidophiles), saturating salt concentrations (extreme halophiles) and strictly anaerobic conditions (methanogens). Archaea were not expected to be found in 'ordinary', non-extreme environments. So when the rRNA cloning and sequencing method was applied to ocean midwater samples (100 and $500 \mathrm{~m}$ water depths) for the first time, using 'universal' PCR primers, it was a complete surprise that many of the sequences obtained originated from Archaea and not Bacteria (Fuhrman et al. 1992). In that study, 5 out of 7 random clones from $500 \mathrm{~m}$ depth and 2 out of 10 from 1 of 3 samples taken at $100 \mathrm{~m}$ water depth were found to belong to the Crenarchaeota, the group previously assumed to contain only extreme thermoacidopiles. Shortly afterwards, related Crenarchaeota (named Marine Group I), plus members of the Euryarchaeota (named Marine Group II), were detected in shallow coastal waters by Archaea-specific PCR, and reported to represent $<2 \%$ of the prokaryotic community in that environment (Delong 1992). Fuhrman et al. (1992) suggested that the high proportion of archaeal clones from $500 \mathrm{~m}$ water depth pointed to a high potential abundance and resulting impact of this group on deep sea metabolism, but it was uncertain if relative clone abundance was suitable to draw such conclusions. Numer- ous nucleic acid hybridization studies indicated high proportions and dynamism of Archaea in deeper waters and the Antarctic (e.g. Massana et al. 1997, Murray et al. 1998), but quantitative hybridization has its own uncertainties regarding the measurement of cellular abundance. The high abundance was confirmed most convincingly by direct cell counts via fluorescent in situ hybridization (FISH). Such studies reported that Archaea are remarkably abundant, particularly in ocean midwaters (usually depths below $100 \mathrm{~m}$ ), represent typically 20 to $40 \%$ of the cells visible by epifluorescence at such depths (often exceeding bacterial abundance), and are highly dynamic (Fuhrman \& Ouverney 1998, DeLong et al. 1999, Karner et al. 2001, Herndl et al. 2005, Teira et al. 2006a). So Archaea are not just some rare type of cell, but rather constitute a major part of the prokaryotic community, especially in the deep sea and some colder, shallower waters. The number of marine Archaea globally has been calculated to total about $10^{28}$ cells, a mind-boggling quantity. Lined up like beads on a string, these Archaea would stretch longer than the entire Milky Way galaxy (to borrow a comparison from Suttle 2007)! So the question arises - just what are these Archaea doing? In other words, how does one link their identity to their function?

The first direct measures of archaeal activity were made by a combination of autoradiography and FISH (Substrate Tracking AutoRadiographic FISH: STARFISH), and showed that about $60 \%$ of the Archaea from $200 \mathrm{~m}$ depth in the NW Mediterranean Sea and Monterey Bay (California) took up a mixture of tritiated L-amino acids, added to seawater samples at nM concentrations (Ouverney \& Fuhrman 2000). Recent similar studies with improved sensitivity and covering extensive areas (and a wide range of water depths) in the North Atlantic showed that the Archaea (Eury- and Cren-) take up both D- and L- amino acids (Teira et al. 2004, 2006b, Herndl et al. 2005). These studies suggest that Crenarchaea have heterotrophic capabilities and in fact compete successfully with Bacteria for the extremely low concentrations of dissolved amino acids in these waters. However, other evidence, initially from geochemical studies, suggested a very different situation. Because Archaea have unique lipids that can be extracted and studied individually, investigation of the properties of particular kinds of Archaea, using chemical characteristics including isotopic content, is possible. Pearson et al. (2001) reported that the ${ }^{14} \mathrm{C}$-content of archaeal isoprenoids from Santa Monica Basin (California) surface sediments indicated that the Archaea incorporated inorganic carbon chemoautotrophically below the euphotic zone. Kuypers et al. (2001) examined fossil marine archaeal lipids and concluded, based upon ${ }^{13} \mathrm{C}$-content, that 
Archaea were living chemoautotrophically during a Cretaceous ocean anoxic event. Direct measurements on live marine Archaea, grown in coastal mesocosms under controlled conditions $\left(15^{\circ} \mathrm{C}\right.$, dark $)$, provided additional evidence: Wuchter et al. (2003) showed that ${ }^{13} \mathrm{C}$-bicarbonate was incorporated into archaeal lipids. Herndl et al. (2005) reported significant ${ }^{14} \mathrm{C}$ bicarbonate incorporation into Archaea in deep sea field samples. Together, these studies have made it clear that the Archaea have a significant chemoautotrophic capability.

This raises the obvious question about what kind of chemoautotrophy is involved. Interestingly, the initial answer to this did not come from a study focusing on Archaea, but from the shotgun metagenomic survey of the Sargasso Sea by Venter et al. (2004). In that study, the entire microbial community $(0.1$ to $0.8 \mu \mathrm{m})$ from near the sea surface was collected by filtration and the DNA extracted, sheared, cloned, and $>6$ billion bases of DNA sequence generated and assembled (only a small fraction overlapped sufficiently to assemble). Venter et al. (2004, p. 73) reported '... because it has been believed that only members of the bacterial domain were capable of oceanic nitrification, it is interesting to note that an ammonium monooxygenase gene was found on an archaeal-associated scaffold within our data set.' In other words, their assembler put together several DNA fragments that included genes of archaeal origin, and among these genes was ammonia monooxygenase, the enzyme that catalyzes the first, critical step in oxidation of ammonia to nitrite. This was an incredibly exciting discovery because until that time, ammonia oxidation was thought to be carried out only by members of the domain Bacteria. However, the evidence from the Venter et al. (2004) study alone was not fully conclusive, because it was possible that the gene might have actually been for methane oxidation (the 2 genes are related), or that the scaffold might have been some sort of chimera - and as Carl Sagan was famous for saying in his television series, Cosmos, 'Extraordinary claims require extraordinary proof.' But such evidence developed quickly. The result was confirmed by more conclusive data, most notably the sequence of a large-insert metagenomic clone from soil that included a crenarchaeal 16S rRNA gene, the ammonia monooxygenase (amoA) gene, plus some other related genes like nitrite reductase (Schleper et al. 2005). Yet even that was not as convincing as the isolation of a Marine Group I crenarcheon, later named Nitrosopumilus maritimus, from the rocky substrate of a marine aquarium, where it grew autotrophically by the oxidation of ammonia to nitrite (Konneke et al. 2005). Thus, some Archaea are indeed capable of ammonia oxidation. Further confirmation of this capability, together with other valuable information about autotrophic and mixotrophic functionalities, has come from the metagenomic analysis of Cenarchaeum symbiosum, an uncultivated marine archaeon that lives symbiotically within a sponge (Hallam et al. 2006).

What about the evidence on amino acid uptake in nature? Are the Archaea mostly autotrophs or mostly heterotrophs? Ingalls et al. (2006) evaluated the natural ${ }^{14} \mathrm{C}$-content of specific planktonic marine archaeal lipids in order to estimate autotrophic and heterotrophic contributions to their metabolism. Getting enough material for the analysis required filtering an astonishing 2000001 of seawater from $670 \mathrm{~m}$ water depth off Hawaii through a $0.2 \mu \mathrm{m}$ pore size filter. The calculations required a model and several assumptions that were reasonable, but not certain. The authors concluded that $83 \%$ of the crenarchaeal carbon was derived from bicarbonate at the sampling depth, and the remaining $17 \%$ from 'modern', recently fixed carbon originating from the euphotic zone. This result applies specifically to the $670 \mathrm{~m}$ depth, and probably cannot be generalized (see below). It also does not say whether most of the Marine Group I Crenarchaea are pure autotrophs, with only some heterotrophs in the group, or if all them have some heterotrophic capability.

A different kind of analysis also addressed the question whether all Marine Group I Crenarchaea are ammonia oxidizers. Wuchter et al. (2006) and Herfort et al. (2007) compared crenarchaeal counts with amoA gene copy numbers by QPCR, and found that they were highly correlated. Their data suggested 2.8 times as many amoA genes as crenarchaeal $16 \mathrm{~S}$ genes in this group, or 2.5 amoA copies per cell counted by CARD FISH. So if the data are accurate and all the cells have the gene, it suggests 2 to 3 copies per cell (assuming a single 16S gene per cell). It is possible that only some cells have the gene, but with a higher number of copies.

It is remarkable how rapidly we have learned about marine Archaea, as shown by accelerating discoveries in the past few years (Fig. 1). But what do all these data mean for understanding the activities of marine Crenarchaeota? While it is not possible to be sure when comparing different studies, a parsimonious interpretation of the data suggests that, in the top several hundred meters of the sea which have been studied most extensively, the large majority of Marine Group I Crenarchaea probably possess the amoA gene and are capable of ammonia oxidation, and also have the ability to take up and incorporate dissolved L- and Damino acids. We speculate that these processes occur either simultaneously or closely spaced in time in the same cell. Interestingly, G. J. Herndl et al. (pers. comm.) have noted that, as depth increases from a few 


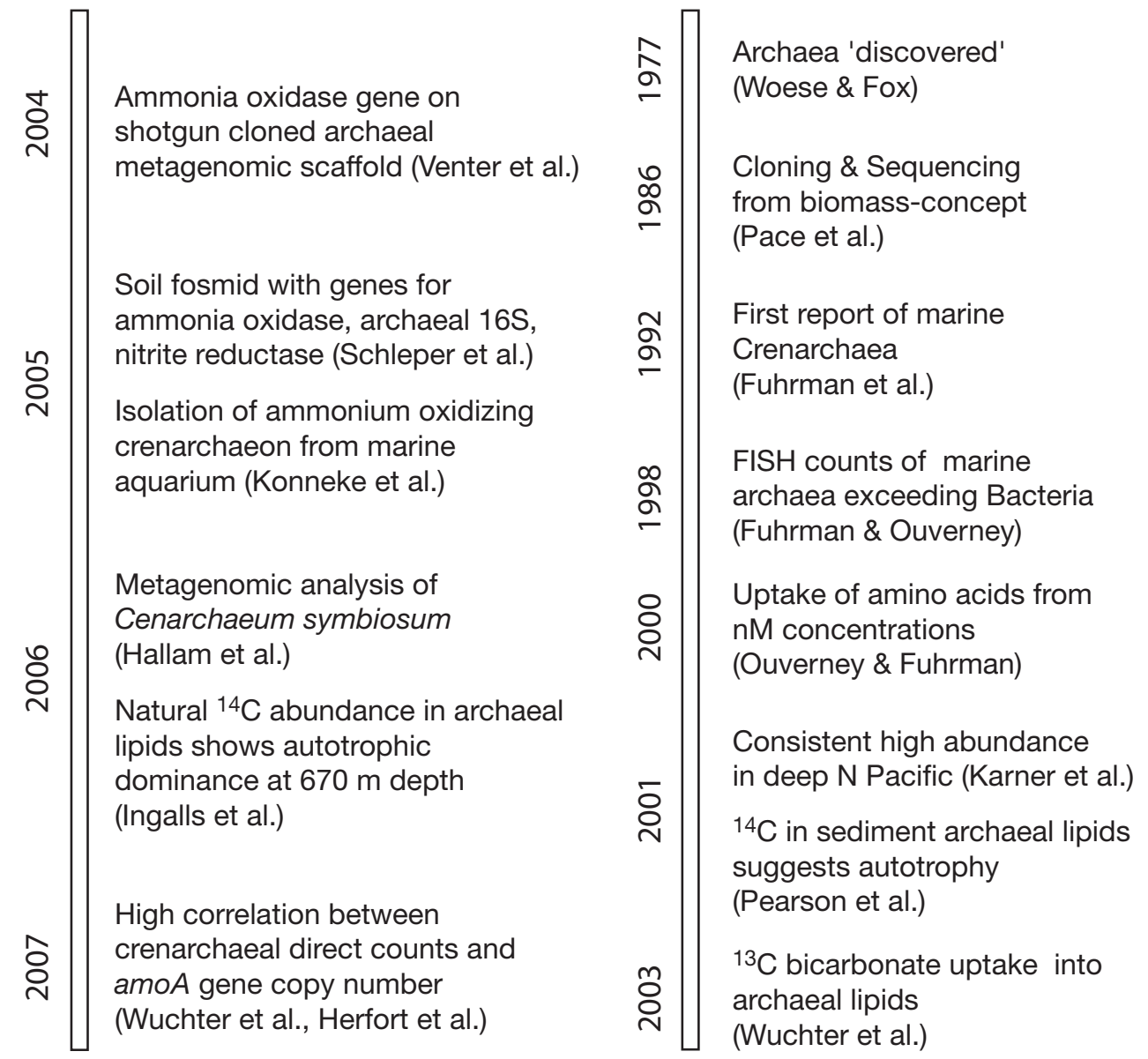

Fig. 1. Marine Crenarchaeota. Timeline for selected discoveries starting at the upper right corner

hundred meters to $3000 \mathrm{~m}$, the presence of the $a m o A$ gene drops much faster than the number of crenarchaeal 16S rRNA genes, with the ratio dropping from $\sim 2$ to $<0.1$. The implication of this observation is that most or all Crenarchaea occurring in the top few hundred meters of the ocean may have the potential to be ammonium oxidizers, but only a small portion of those occurring deeper have this capability. This seems plausible, considering that a large part of ammonium gets metabolized at shallower depths and only small amounts reach the deep sea. However, the same argument could be made for organic carbon, so the explanation is not fully clear. It is possible that the presence or absence of the amoA gene in the Crenarchaea is related to the $\mathrm{C}: \mathrm{N}$ ratio of sinking organic matter, which typically increases with depth, suggesting relatively less $\mathrm{N}$ as depth increases (Honjo \& Manganini 1993); but some reports indicate that $C$ and $\mathrm{N}$ degrade in sinking material at similar rates (Hernes et al. 2001). In any event, we expect that the relative extent of heterotrophy vs. autotrophy probably depends on environmental conditions, notably the avail- ability of ammonium (and oxygen) compared to usable organic compounds. In environments with chronic shortages of ammonium (e.g. as encountered by plankton at the deepest depths), the ammonium oxidation pathway genes might be considered unnecessary baggage that can only rarely, if ever, be used, and thus are easily lost. In contrast, the heterotrophic pathways are more generally usable, so are less likely lost. Overall, it seems that even though Crenarchaea are probably the major ammonia oxidizers in the world (see review by Francis et al. 2007), there may be many places where they do not possess the capability.

\section{CASE STUDY 2: PROTEORHODOPSIN}

One of the most interesting and unexpected early discoveries from metagenomics was the presence of proteorhodopsin (PR) genes in marine planktonic Bacteria (Beja et al. 2000). This was unexpected, because rhodopsin-like proteins had formerly only been known from eukaryotes or rare halophilic Archaea that in- 
habit hypersaline niches. In eukaryotes, rhodopsins function as light sensors (e.g. in the human eye), and in halophilic Archaea these proteins function as lightdriven transporters or photosensory pigments. Rhodopsin-like pigments are 7-helix trans-membrane apoproteins (opsins), capable of binding all-trans-retinal (vitamin A aldehyde) inside the membrane-embedded helices (opsin proteins bound to retinal are called rhodopsins) (Spudich et al. 2000). Upon illumination, the bound retinal molecule in rhodopsins undergoes light-induced isomerization, inducing conformational changes in the protein backbone and causing translocation of a proton (or other ion, like chloride) across the membrane, or signaling to transducer proteins.

When the initial PR gene found by Beja et al. (2000) was cloned and expressed in Escherichia coli, after providing the organism with exogenous retinal, the PR started pumping protons from the inside to the outside of the cell when illuminated. Subsequent studies have shown that this proton gradient can be used to phosphorylate ADP to ATP in such clones (Martinez et al. 2007). Another important observation is that the wavelengths of light that are maximally absorbed by PR can be 'tuned' by the alteration of key amino acids (Man et al. 2003), permitting the protein to optimize energy capture in environments dominated by green or blue light. Shallow or coastal waters tend to be greenish, while deeper areas are dominated by blue light. As a consequence, marine PRs include many near-surface forms that absorb maximally in the green, and deepeuphotic-zone forms that absorb maximally in the blue range of the light spectrum (Man et al. 2003). Furthermore, the 'Sorcerer II' near-surface ocean metagenomic survey, covering a transect from Halifax through the Panama Canal to the Eastern Tropical Pacific, reported over 2600 PR genes that were dominated by green-absorbing types in nearshore waters and dominated by blue-absorbing types in offshore ('blue') waters (Rusch et al. 2007). PR has been found in members of many of the most common marine bacterial groups, including the ubiquitous SAR11 and SAR86 surface clades (Beja et al. 2000, Giovannoni et al. 2005), marine Euryarchaeota (Frigaard et al. 2006), Planctomycetes (McCarren \& DeLong 2007), Betaproteobacteria (McCarren \& DeLong 2007), the predominately coastal SAR92 clade (Stingl et al. 2007), the marine Roseobacter group (Moran \& Miller 2007), and at least 3 representatives from the widespread class Flavobacteria within the phylum Bacteroidetes (Dokdonia sp., Polaribacter sp. and Leeuwenhoekiella blandensis) (Gomez-Consarnau et al. 2007). Taken together, these clades typically comprise $50 \%$ or more of the total bacteria in marine surface waters (Giovannoni \& Rappe 2000). PR is also present in minor prokaryotic components of the marine community
(Venter et al. 2004, Rusch et al. 2007). The phylogenetically widespread distribution, even across domains, suggests that horizontal gene transfer of this gene is common (Frigaard et al. 2006), and implies that the gene confers a significant advantage to the cell. However, it also suggests that the gene is not diagnostic of a particular clade, and we do not know which members of which clades possess it or express it. PR abundance estimates from individual metagenomic samples collected from various ocean waters have ranged from as little as $2 \%$ to more than $100 \%$ (perhaps implying the presence of more than one PR gene per cell) of the estimated total number of Bacteria plus Archaea (Sabehi et al. 2005, Rusch et al. 2007, Fuhrman et al. 2008), and conservative quantitative PCR analysis suggests that about half of the Bacteria and Archaea in the Sargasso Sea and $23 \%$ elsewhere in the North Atlantic possess the gene (Campbell et al. 2007).

These observations all raise the intriguing prospect that considerable solar energy might be harvested by $\mathrm{PR}$, potentially allowing cells to grow more efficiently, and thus having an important role in global ecosystem models and energy budgets. At this time, however, direct evidence for a broad energetic role in most Bacteria or Archaea is lacking.

One might expect that cells that benefit energetically from PR would grow faster in the light compared to the dark. Interestingly, of the 4 examined pure cultures that express PR tested to date, only one shows faster growth in the light. The 3 that do not (Pelagibacter ubique in the alphaproteobacterial SAR11 cluster, HTCC2207 in the gammaproteobacterial SAR92 clade, and HTCC2181 in the betaproteobacterial OM43 cluster) grow in low-nutrient, filtered seawater at the same rate and with the same yield whether cultured in the light or dark, even though the cells are thought to be limited by the availability of carbon (Giovannoni et al. 2005, Stingl et al. 2007, Giovannoni et al. 2008). The culture that is reported to grow faster in the light is Dokodonia (in the Flavobacteria), and that organism actually showed no growth under dark conditions (grown in unenriched filtered seawater), but grew reasonably well in the light. When grown in artificial seawater, the light:dark yield ratio was 1 for very low (0.06 mM) and high (242 mM) organic carbon media, but up to 4 at intermediate levels of organic carbon (0.14 to $1.1 \mathrm{mM}$ ) (Gomez-Consarnau et al. 2007).

In addition to these studies of pure cultures, there have also been mesocosm studies of the effects of light on the growth of various marine bacteria in natural seawater, following the different phylotypes of bacteria individually by using Amplified Ribosomal Intergenic Spacer Analysis (ARISA), a genetic fingerprinting method. (Schwalbach et al. 2005) studied bacteria in samples from meso- and oligotrophic areas of the 
eastern Pacific in 201 mesocosms under light or dark conditions for 5 to $10 \mathrm{~d}$. They found that most members of groups reported to possess PR (e.g. SAR11, SAR86, Bacteroidetes) actually showed more net growth under dark conditions, with only a few members growing more under light conditions. The only phylogenetic group consistently growing better in the light were the Cyanobacteria (no surprise). These results are consistent with the work on pure cultures mentioned above (Giovannoni et al. 2005, 2008, Stingl et al. 2007, Gomez-Consarnau et al. 2007), where different PRcontaining taxa showed different light/dark responses, with the majority not having a positive response of growth to light.

Although many marine PRs can act as light-driven proton pumps, there is still uncertainty about when, or even if, this provides substantial energy to most organisms that possess and express the gene. Most marine PR genes that have been examined closely have proton-pumping characteristics, which includes the amino acid residues thought to be important for this function, and a 'fast' photocycle time, which refers to the time it takes the protein to return to its original state after its light-induced conformational change (Sabehi et al. 2005). But several marine PR-like genes in metagenomic datasets lack key amino acids in the retinal binding pocket, similar to known sensory rhodopsins, and some also have what appear to be a sensory transducing gene adjacent to the PR gene (Spudich 2006). It should be noted that some archaeal sensory rhodopsins, which do not pump protons in their native cell, can pump protons when expressed in the bacterium Escherichia coli without their corresponding transducing molecules (Spudich 1994). Therefore, one must be careful in interpreting heterologous expression studies as proof of function. It is probably also important to bear this in mind for proteins besides PR. In any case, we cannot rule out a sensory role for many marine PRs.

Note that with PR as a potential energy source, one would expect a growth benefit only if cells are energy limited and not limited by nutrients like P, N, or Fe. Yet such nutrients are thought to limit bacterial growth (even heterotrophic bacteria) in many parts of the sea (Pomeroy et al. 1995, Pakulski et al. 1996, Cotner et al. 1997, Thingstad et al. 1998, Kirchman et al. 2000). Consequently, the advantages - if any — of PR in such places still need to be explored.

So which organisms can we say for sure possess PR, and what function(s) do we link to it? There is no clear answer to either question. PR appears widespread in the SAR11 cluster and distributed widely in other clades. The answer about functions quite possibly lies in multiple strategies in different organisms. It appears that some organisms, like Dokodonia, use PR to pro- vide considerable energy for growth (Gomez-Consarnau et al. 2007), and these organisms might sometimes rely on PR and light to express net growth (analogously to the way that cyanobacteria rely on chlorophyll and light for growth, even if carbon fixation may not be involved in Dokodonia). Other organisms, probably including members of the SAR11 cluster, probably do not rely on PR and light for growth, and may not even show a clear growth benefit under many typical ocean conditions. It is possible that, in these cells, PR provides a valuable energetic benefit mostly under extremely low organic carbon conditions, permitting the cell to keep up critical functions like DNA repair, and thus survive when otherwise they may not. It is also possible that, in other cells, PR is largely regulatory or sensory, detecting when the cell is in the euphotic zone during daytime and switching functions most suitable for those conditions on or off. One might even imagine that some viruses could use light sensory functions to delay the assembly and release of virions from cells until the onset of darkness, because light damages viral DNA but such damage is repaired as long as the viral DNA is in the bacterial host. Releasing virions in the evening would give them maximal time in the dark to diffuse to new hosts without suffering light damage. PR may have other functions that have not yet been revealed, and it is possible that PR serves multiple functions in some organisms. There is certainly much to learn about the marine PRs.

\section{USING DISTRIBUTION PATTERNS TO LINK IDENTITY WITH FUNCTIONS}

While it is difficult to link most complex functions with particular microorganisms directly, an alternative approach is to examine the distributions of various organisms and environmental parameters over space and time, and to correlate subsequently which functions go with which organisms. The first step is simply to look for patterns in distributions, to see the appropriate scales of variability and learn what a particular sample might represent. For example, is a 11 sample representative of a cubic meter, or a region hundreds of meters or several kilometers wide? Similarly, how quickly do communities change-over hours, days or weeks? Such questions have been investigated in our lab primarily with community fingerprinting approaches, mostly ARISA. Scales of variability often can, by themselves, hint at factors controlling community composition.

It makes sense to first briefly describe what ARISA fingerprinting can demonstrate. We have found that ARISA can distinguish taxa (actually operational taxonomic units, or OTUs) with $16 \mathrm{~S}$ rRNA sequence similarity of about $98 \%$ or less, similar to what many con- 
sider near the 'species' level for Bacteria (Brown \& Fuhrman. 2005). We have also found that our highly standardized version of the method is generally quantitative, especially when comparing how the amount of a particular OTU changes between different samples (as opposed to comparing the amount of one OTU vs. another). To do this, we compared flow cytometric and ARISA-based estimates of the abundance of Prochlorococcus at our San Pedro Ocean Time Series (SPOT) station monthly over $3 \mathrm{yr}$. The linear regression of these variables had an $\mathrm{r}^{2}$ value of 0.86 , indicating that the ARISA provided an excellent measure of Prochlorococcus abundance (Brown et al. 2005). While the method is not perfect and might miss certain taxa that do not have linked 16S and 23S rRNA genes (e.g. most Planctomycetes and close relatives), it provides a reasonably comprehensive picture of the bacterial community in most marine samples.

ARISA fingerprints indicate that, in the places studied to date, bacterial communities occur in coherent spatial patches of horizontal extents ranging from a few $\mathrm{km}$ to about $50 \mathrm{~km}$ at a given depth (Fig. 2). This preliminary conclusion is based primarily on studies in oligotrophic surface waters. In the oligotrophic open Pacific, we found that the similarity of communities from 2 stations ( 7 replicate 201 samples each), collected as the ship drifted over a distance of about $2 \mathrm{~km}$, was 85 to $95 \%$
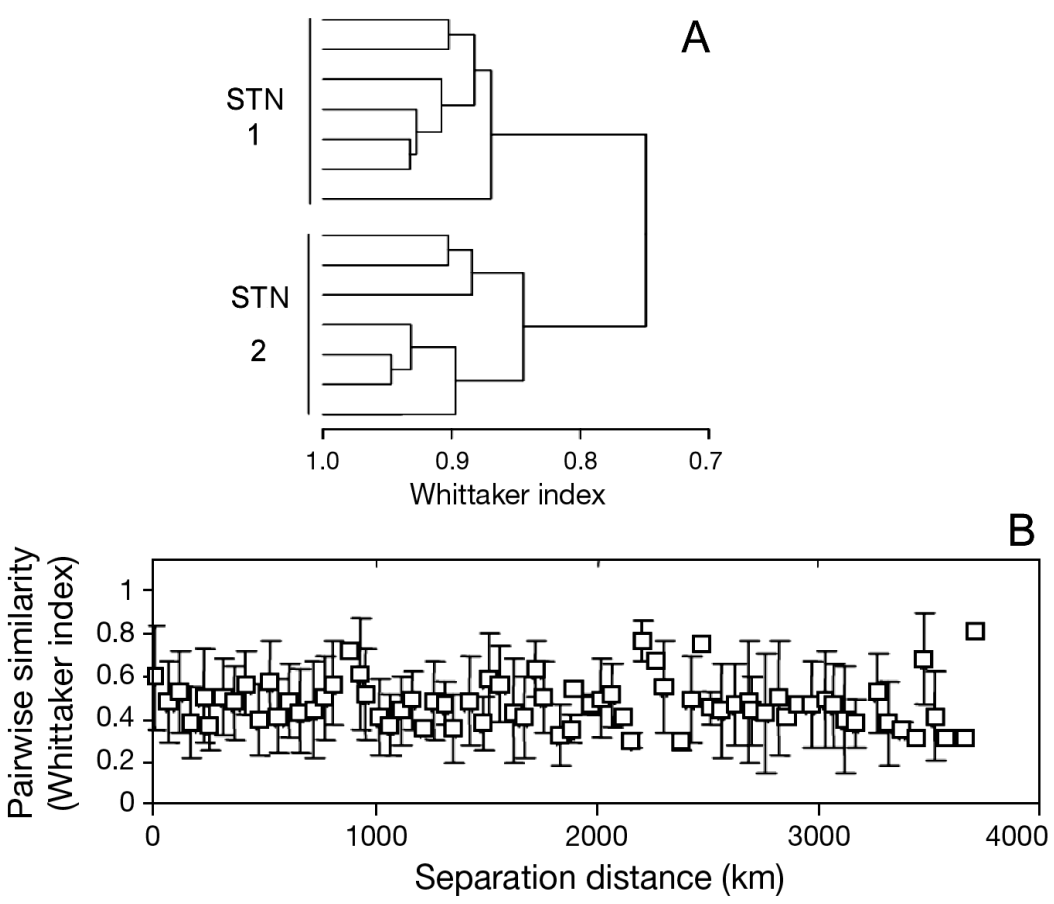

Fig. 2. (A) ARISA-based community similarities among 7 replicate near-surface 201 samples from 2 stations in the central North Pacific Ocean. Similarity was measured using the Whittaker Index. (B) ARISA-based similarity, plotted as a function of distance between sampling locations, also using the Whittaker Index. Modified from Hewson et al. (2006) within stations and $75 \%$ between stations (Fig. 2A and Hewson et al. 2006). For this study, similarity was compared using the Whittaker Index, which takes into account identity and proportions of all OTU. We also noted that in both Pacific and Atlantic surface waters, the similarities of community composition of stations $>50 \mathrm{~km}$ apart were low, typically about $40 \%$, and this similarity did not vary much whether the stations were $50 \mathrm{~km}, 250$ km, or even $1000 \mathrm{~km}$ apart (Fig. 2B and Hewson et al. 2006). Our interpretation of these data was that, within a few $\mathrm{km}$, there is a coherent patch with a particular community composition, but once one leaves that patch, the community is quite different. This suggests that factors with spatial scales $<10 \mathrm{~km}$ or so appear to be most important in the development and maintenance of particular microbial communities. This is similar to the spatial extent of typical mesoscale eddies of chlorophyll as seen from satellites, so the controlling factors may relate to physical mesoscale eddies, the equivalent of the 'weather' in the sea. While these patches are apparently set up and maintained by physical factors, biological interactions within each eddy seem to lead to unique combinations of dominant microorganisms. It will be interesting to see if these conclusions, which are based upon relatively few data, will hold up to broader studies.

The relationship between distance and community similarity described above, where communities jumped from being very similar in nearby samples to being very different at distances above $50 \mathrm{~km}$, is typical of open ocean samples (Hewson et al. 2006). However, similarity at one location appeared to decrease nearly linearly with distance. That occurred when several samples were compared across the shallow and narrow Torres Strait between Australia and Papua New Guinea, separating the Arafura Sea (Indian Ocean) from the Coral Sea (Pacific Ocean). Hewson et al. (2006) concluded that this may be due to the observation of a 'mixing curve' between 'endpoint' Indian and Pacific Ocean communities. It is not yet known to what extent the differences between these communities represent different functionalities, and what those differences might be.

Temporal variation has also been examined on scales from days to years. Lee \& Fuhrman (1990), using DNA/ DNA hybridization of whole communities, found that communities collected 1 wk apart from Long Island Sound, New York, were 92 to $94 \%$ similar to 
each other, while samples collected 7 mo apart were only 33 to $57 \%$ similar. Samples from the same location collected 2 wk apart were only about $40 \%$ similar (Lee \& Fuhrman 1991). The authors also reported that, of open ocean samples collected from $25 \mathrm{~m}$ water depth at one geographic location over 3 consecutive days, those from Days 1 and 2 were $>90 \%$ similar to each other, while samples collected on the third day were only 50 to $70 \%$ similar to those collected on the other 2 days, respectively. Part of the difficulty in interpreting these studies (and others described above) is the separation of spatial from temporal changes, because patches can drift with currents and no ship can simultaneously sample over a large region.

To examine temporal variability, Hewson et al. (2006) performed 7 drifter studies of 24 to $360 \mathrm{~h}$ duration in the oligotrophic Gulf of Mexico, the North Pacific and the West Tropical Atlantic, and analyzed the samples using ARISA. The similarity indices between assemblages collected over time in the same drifter changed on average by a Sorensen index of $0.12 \mathrm{~d}^{-1}$ (comparing the presence/absence of, OTU and a Whittaker index of $0.17 \mathrm{~d}^{-1}$ (comparing proportions in various OTUs) per fingerprint across all surface drifter studies. We found similar or smaller daily changes in community composition in Southern California coastal waters sampled at one geographic location over a period of about $1 \mathrm{wk}$, or when following drifters over a period of a few days (J. A. Steele \& J. A. Fuhrman unpubl.). Overall, these results suggest that, most of the time, there are modest day-to-day changes in community composition.

We have found that month-to-month variation at our SPOT site provides particularly valuable information on relationships among organisms and environmental parameters like temperature and nutrients. The monthly patterns of community composition in nearsurface (5 m water depth) samples were studied over 4 yr using a statistical technique called discriminant function analysis (DFA), linked with autocorrelation and multiple regression (Fuhrman et al. 2006). DFA was performed to evaluate whether it was possible to 'predict' the month based on the bacterial community composition, and in fact several subsets of the bacterial community, collectively including most of the taxa, did this very well with 80 to $100 \%$ accuracy. Autocorrelation was high at a 1 mo lag, showing significant similarities from month to month in community composition. With a 3 mo lag, there was little or no autocorrelation, and by 5 mo lag, the autocorrelation was negative, indicating a shift to a very different community in the 'opposite' season (Fig. 3). Most interestingly, the autocorrelation coefficient returned to a significant positive value with a lag of 10 or $11 \mathrm{mo}$, and varied sinusoidally with a period of a year. This indicates that the community predictably returned to a similar composition during the same season in consecutive years. Multiple regression showed that the community composition could often be predicted well $\left(\mathrm{r}^{2} \approx 0.7\right)$ from parameters like temperature, salinity, inorganic nutrients, chlorophyll, bacterial and viral abundances. The predictability indicates that different bacteria indeed have different niches, with limited redundancy, otherwise different combinations of bacteria would appear under the same conditions and prediction would be difficult. Different subsets of the community could be predicted from different combinations of parameters, allowing us to start evaluating which bacteria thrive under which conditions.

\section{NETWORKS}

The statistical relationships among microorganisms, and between microbes and other parameters, permit us to differentiate the organisms in terms of their preferred conditions, and also to assign microbes into groupings that tend to co-occur and those that do not occur together (non-randomly). The information to elucidate these groupings is available from simple corre-
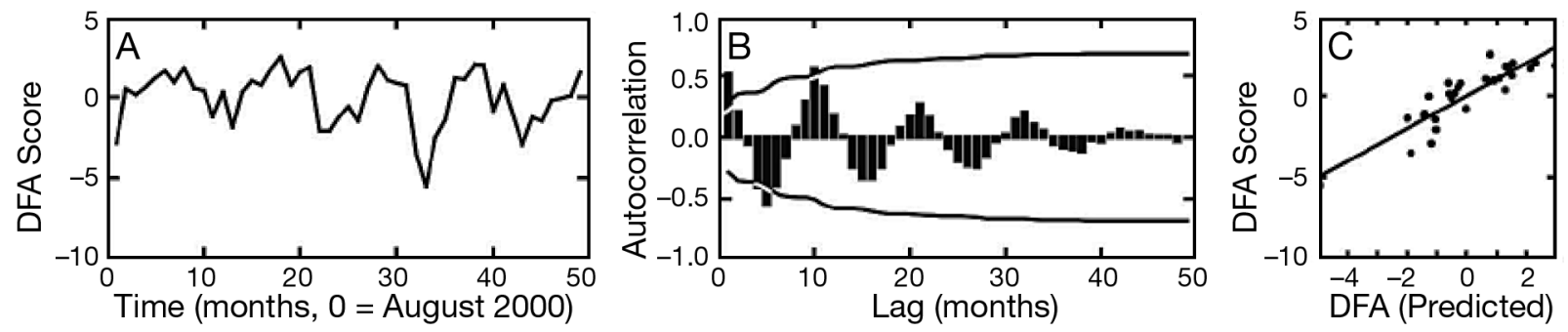

Fig. 3. Bacterial community composition at the San Pedro Ocean Time Series (SPOT) site at $5 \mathrm{~m}$ water depth: results of Discriminant Function Analysis (DFA), Time Series Analysis (Autocorrelation), and Multiple Regression Analysis for a 4 yr time series. (A) First discriminant function (DFA1, a measure of bacterial community composition) over time; (B) autocorrelation of DFA1 with various time lags, pairwise comparisons among all possible pairs of samples; line represents the $\mathrm{p}<0.05$ significance level. (C) Actual DFA1 vs. predicted DFA1 using multiple regression from parameters including temperature, salinity, nutrients, chlorophyll, viral and bacterial abundance; $\mathrm{r}^{2}=0.7$. Modified from Fuhrman et al. (2006) 
lations between organisms as individual OTU change over time, so again we can use our time series data to help characterize properties of particular taxa. We have found that it is particularly valuable to look not only for correlations of co-occurrence at each time point, but also for correlations that may be lagged in time -i.e. when one organism tends to follow another, or tends to decline after another one increases. Ruan et al. (2006) developed a mathematical method called Local Similarity Analysis (LSA) to permit evaluation of such time-lagged relationships, and showed, using examples from SPOT, how LSA can detect significant relationships that would be missed if time lags are ignored. Furthermore, by examining the pairwise relationships revealed by LSA, it is possible to draw an interaction diagram, or network diagram, that indicates the positive and negative mathematical relationships among microorganisms and between microbes and environmental parameters (Ruan et al. 2006). In a sense, this is a diagram of the 'niche space' of the various organisms, and we believe that it provides a very powerful tool for the examination of the 'natural history' of microbes in their complex wild habitats.

Additional examples for these mathematical relationships among bacteria and between bacteria and environmental parameters beyond those described by Ruan et al. (2006) are shown in Fig. 4. The figure is based on data collected as described by Fuhrman et al. (2006), with 36 samples from the chlorophyll maximum depth (average $32 \mathrm{~m}$ ), collected approximately monthly between September 2000 and March 2004. Mathematical analytical methods are described in Ruan et al. (2006), and images were generated using Cytoscape (www. cytoscape.org). In these bacterial community network interaction diagrams, a few selected bacterial target groups are presented as central nodes, and only their nearest neighbors in the network are shown. These nearest neighbors are organisms or parameters with a direct or time-lagged significant positive or negative correlation ( $\mathrm{p}<0.05$, by permutation tests) with the individuals of the target group. Some interesting relationships are apparent. First note that there are 10 different SAR11 types, each with unique combinations of relationships to other organisms and parameters (Fig. 4A). This suggests that there are probably at least 10 different 'ecological species' of SAR11 at our study site; an observation that contrasts with a few broadly defined types of SAR11 that have been reported to respond differently to different environmental conditions elsewhere (e.g. Mor-

\section{A SAR11 Cluster}

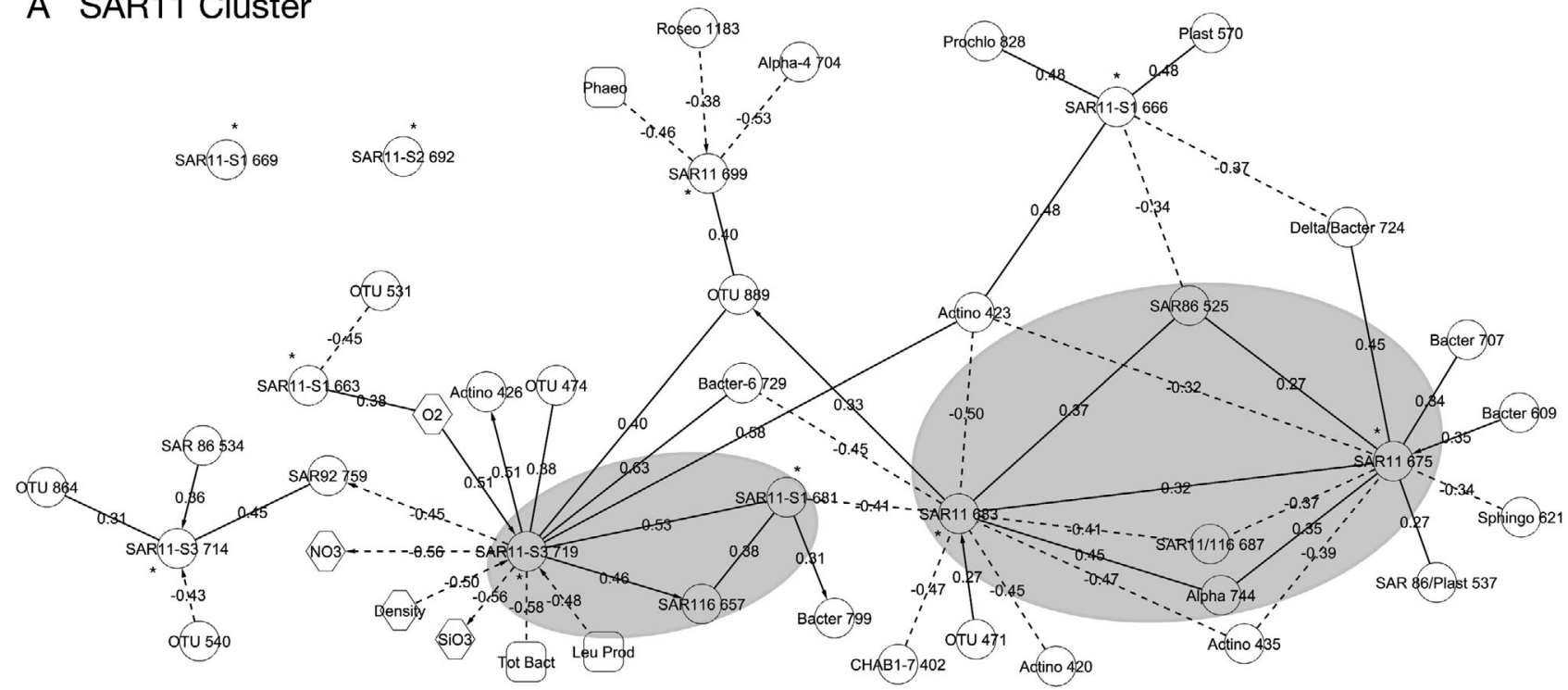

Fig. 4. (Above and following page.) Bacterial community network interaction diagrams based on San Pedro Ocean Time Series (SPOT) data, analyzed by Local Similarity Analysis (LSA). ( ${ }^{*}$ ) Central nodes (members of the target group for each figure, i.e. SAR11 cluster in A). Only nearest neighbors, i.e. parameters that correlated significantly $(p<0.05$, by permutation tests) with central nodes, are shown. Circles: bacterial OTU, hexagons: abiotic environmental parameters, squares: biotic environmental parameters, (-) positive correlations, (---) negative correlations, arrows indicate a 1 mo time lagged correlation, with the arrow pointing from the earlier to the later parameter. Numbers on lines are LSA correlation values, normalized to a -1 to +1 scale. Grey-shaded areas show where 2 members of the target group correlate positively with each other and share multiple positive correlations to other bacteria, as discussed in the text. Actino: Actinobacteria; Alpha, Delta, Gamma: types of Proteobacteria; Altero: Alteromonas; Bacter: Bacteroidetes; Flavo: Flavobacteria; Leu Prod: leucine-estimated bacterial production; Plast: plastid; Phaeo: phaeopigments; Roseo: Roseobacteria; SAR11 S1, S2, S3: SAR11 cluster surface 1, 2 and 3 subclades; Sphingo: Sphingobacteria; Tot Bact or Tot Vir: total bacteria or virus counts; Temp: temperature; Sal: salinity; Verruco: Verrucobacteria 

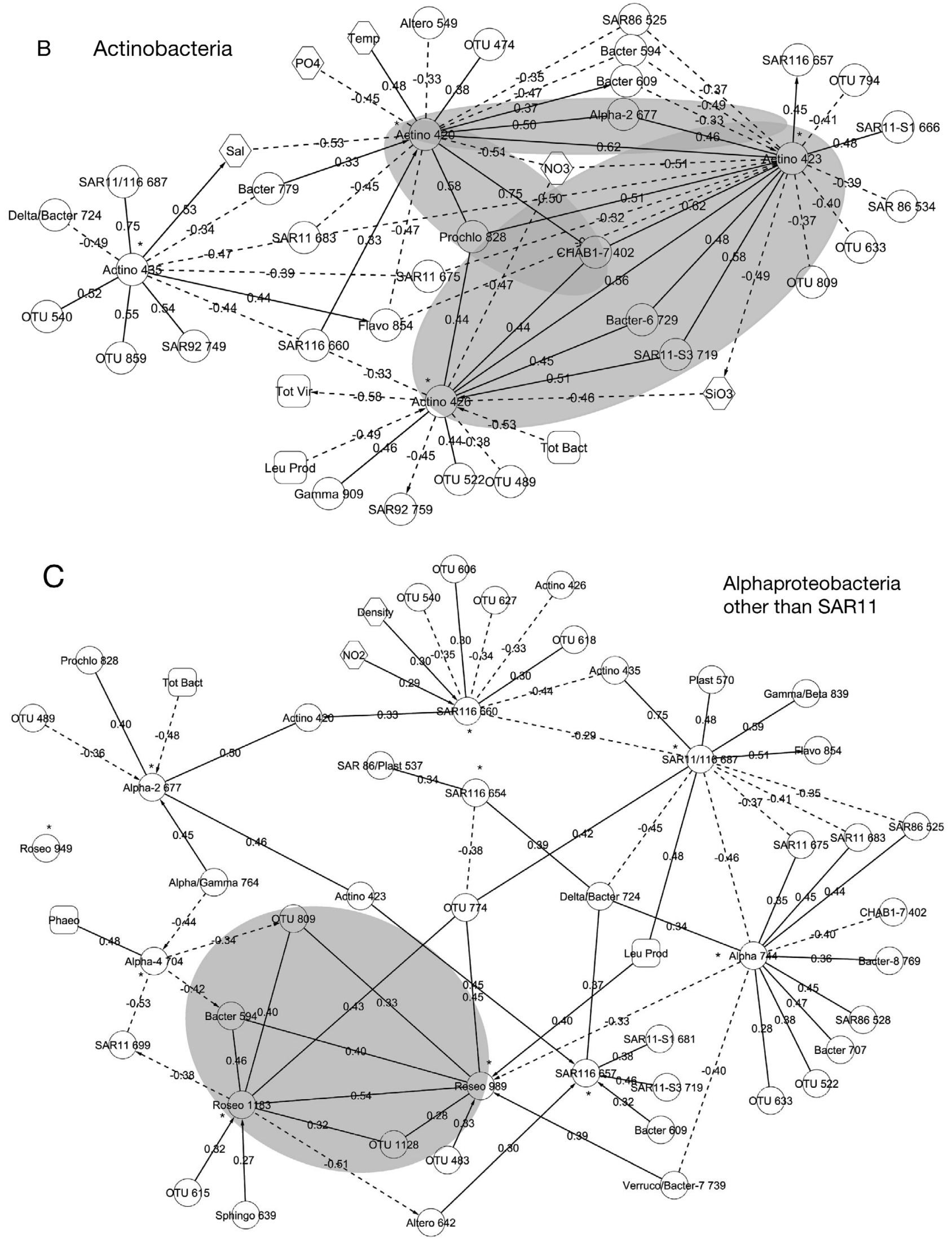

Fig. 4 (continued) 
ris et al. 2005). Interestingly, the 2 most strongly correlated members of the SAR11 cluster also happen to be distantly related to each other phylogenetically, with SAR11 719 belonging to surface cluster 3 and SAR11 681 belonging to surface cluster 1 (see Brown et al. 2005 for phylogenetic tree). Thus, even within a 'narrow' group, ecological relatedness does not necessarily follow phylogenetic relatedness. It can also be seen that some OTUs correlate primarily with other bacteria, while others correlate substantially with different elements of their environment. This may suggest that certain organisms are more influenced by their biotic environment, while others are influenced by their abiotic environment (e.g. physical or chemical forcing). Note that Fig. 4 shows many positive and negative correlations. Positive correlations may represent common preferred conditions or perhaps cooperative activities like cross-feeding, while negative correlations may represent competition for limiting resources, resource partitioning, or perhaps active negative interactions like targeted allelopathy (Long \& Azam 2001). Note that many interactions involve a time lag, and it is likely that careful examinations of these temporal transitions can provide ecological insights as well as fodder for focused experimental design.

Each node and its nearest neighbors that are positively correlated constitute a group of organisms that tend to co-occur over time, like subsets of the ecological community that rise and fall together in abundance. Note that, in most cases, these community subsets include only a single member of the target group for that figure, i.e. 2 members of the same phylogenetic group or cluster are only in some instances directly connected by solid lines, but most are not. To us this suggests that, even though there may be physiological similarities among members of the same cluster, the different members tend to co-occur with different organisms. However, some of these subsets include members of the same cluster as well as a few other organisms that are consistently correlated with both group-mates. These are shown in Fig. 4 with grey shading, and include Actinobacteria 423 and 426, SAR11 683 and 675, SAR11 681 and 719, and Roseobacter 1183 and 989. These subsets may represent very similar organisms that share aspects of their niche, or alternatively might somehow complement or cross-feed each other. Note that some members of these groups (e.g. SAR11 675 and 666) are connected to several members of the same OTU, but with opposite correlations, suggesting possible exclusion mechanism(s) or perhaps niche partitioning.

This analysis is only a start, but we think it is a very promising approach to examining microbial interactions in nature. We are currently expanding this approach to include protists and Archaea in the inter- action networks, yielding a remarkably comprehensive picture of microbial interactions (J. A. Steele et al. unpubl.). We believe that, as environmental microbial databases grow, this sort of analysis will provide a very powerful tool for the examination of complex interactions in nature.

In summary, the combination of molecular fingerprinting techniques and extensive marine sampling permits the evaluation of diversity patterns that have, until now, been undetectable. We have started to investigate what might be considered the natural history of planktonic marine microorganisms, hopefully permitting a more complete understanding of their roles and interactions.

Acknowledgements. This work is the product of several years of collaboration with students, postdocs, and colleagues. In particular, we thank S. H. Lee, C. Ouverney, A. Davis, K. McCallum, I. Hewson, M. Schwalbach, Q. Ruan, A. Patel, C. Chow, M. Brown, M. Beman, S. Naeem, and F. Sun. Support was provided by NSF grants OCE0527034, 0623575, 0648581, and 0703159 .

\section{LITERATURE CITED}

Beja O, Aravind L, Koonin EV, Suzuki MT and others (2000) Bacterial rhodopsin: evidence for a new type of phototrophy in the sea. Science 289:1902-1906

> Brown MV, Fuhrman JA (2005) Marine bacterial microdiversity as revealed by internal transcribed spacer analysis. Aquat Microb Ecol 41:15-23

> Brown MV, Schwalbach MS, Hewson I, Fuhrman JA (2005) Coupling 16S-ITS rDNA clone libraries and ARISA to show marine microbial diversity: development and application to a time series. Environ Microbiol 7:1466-1479

Campbell B, Waidner L, Cottrell M, Kirchman D (2007) Abundant proteorhodopsin genes in the North Atlantic Ocean. Environ Microbiol 10:99-109

Cotner JB, Ammerman JW, Peele ER, Bentzen E (1997) Phosphorus-limited bacterioplankton growth in the Sargasso Sea. Aquat Microb Ecol 13:141-149

DeLong EF (1992) Archaea in coastal marine environments. Proc Natl Acad Sci USA 89:5685-5689

DeLong EF, Taylor LT, Marsh TL, Preston CM (1999) Visualization and enumeration of marine planktonic archaea and bacteria by using polyribonucleotide probes and fluorescent in situ hybridization. Appl Environ Microbiol 65: 5554-5563

Francis CA, Beman JM, Kuypers MMM (2007) New processes and players in the nitrogen cycle: the microbial ecology of anaerobic and archaeal ammonia oxidation. ISME J 1: $19-27$

Frigaard NU, Martinez A, Mincer TJ, DeLong EF (2006) Proteorhodopsin lateral gene transfer between marine planktonic Bacteria and Archaea. Nature 439:847-850

> Fuhrman JA, Ouverney CC (1998) Marine microbial diversity studied via 16S rRNA sequences: cloning results from coastal waters and counting of native archaea with fluorescent single cell probes. Aquat Ecol 32:3-15

Fuhrman JA, McCallum K, Davis AA (1992) Novel major archaebacterial group from marine plankton. Nature 356:148-149 
Fuhrman JA, Hewson I, Schwalbach MS, Steele JA, Brown MV, Naeem S (2006) Annually reoccurring bacterial communities are predictable from ocean conditions. Proc Natl Acad Sci USA 103:13104-13109

Fuhrman JA, Schwalbach MS, Stingl U (2008) Proteorhodopsins: an array of physiological roles? Nat Rev Microbiol 6:488-494

Giovannoni SJ, Rappe M (2000) Evolution, diversity, and molecular ecology of marine prokaryotes. In: Kirchman DL (ed) Microbial ecology of the oceans. Wiley, New York, p 47-84

- Giovannoni SJ, Bibbs L, Cho JC, Stapels MD and others (2005) Proteorhodopsin in the ubiquitous marine bacterium SAR11. Nature 438:82-85

Giovannoni SJ, Hayakawa DH, Tripp HJ, Stingl U and others (2008) The small genome of an abundant coastal ocean methylotroph. Environ Microbiol 10(7):1771-1782

Gomez-Consarnau L, Gonzalez JM, Coll-Llado M, Gourdon P and others (2007) Light stimulates growth of proteorhodopsin-containing marine Flavobacteria. Nature 445: 210-213

Hallam SJ, Mincer TJ, Schleper C, Preston CM, Roberts K, Richardson PM, DeLong EF (2006) Pathways of carbon assimilation and ammonia oxidation suggested by environmental genomic analyses of marine Crenarchaeota. PLoS Biol 4:e95

Herfort L, Schouten S, Abbas B, Veldhuis MJW and others (2007) Variations in spatial and temporal distribution of Archaea in the North Sea in relation to environmental variables. FEMS Microbiol Ecol 62:242-257

Herndl GJ, Reinthaler T, Teira E, van Aken H, Veth C, Pernthaler A, Pernthaler J (2005) Contribution of Archaea to total prokaryotic production in the deep Atlantic Ocean. Appl Environ Microbiol 71:2303-2309

Hernes PJ, Peterson ML, Murray JW, Wakeham SG, Lee C, Hedges JI (2001) Particulate carbon and nitrogen fluxes and compositions in the central equatorial Pacific. DeepSea Res I 48:1999-2023

- Hewson I, Steele JA, Capone DG, Fuhrman JA (2006) Temporal and spatial scales of variation in bacterioplankton assemblages of oligotrophic surface waters. Mar Ecol Prog Ser 311:67-77

> Honjo S, Manganini SJ (1993) Annual biogenic particle fluxes to the interior of the North-Atlantic Ocean; studied at $34^{\circ} \mathrm{N}, 21^{\circ} \mathrm{W}$ and $48^{\circ} \mathrm{N}, 21^{\circ} \mathrm{W}$. Deep-Sea Res II 40:587-607

> Ingalls AE, Shah SR, Hansman RL, Aluwihare LI, Santos GM, Druffel ERM, Pearson A (2006) Quantifying archaeal community autotrophy in the mesopelagic ocean using natural radiocarbon. Proc Natl Acad Sci USA 103:6442-6447

Karner MB, DeLong EF, Karl DM (2001) Archaeal dominance in the mesopelagic zone of the Pacific Ocean. Nature 409:507-510

Kirchman DL, Meon B, Cottrell MT, Hutchins DA, Weeks D, Bruland KW (2000) Carbon versus iron limitation of bacterial growth in the California upwelling regime. Limnol Oceanogr 45:1681-1688

Konneke M, Bernhard AE, de la Torre JR, Walker CB, Waterbury JB, Stahl DA (2005) Isolation of an autotrophic ammonia-oxidizing marine archaeon. Nature 437: 543-546

Kuypers MMM, Blokker P, Erbacher J, Kinkel H, Pancost RD, Schouten S, Damste JSS (2001) Massive expansion of marine archaea during a mid-Cretaceous oceanic anoxic event. Science 293:92-94

Lee S, Fuhrman JA (1990) DNA hybridization to compare species compositions of natural bacterioplankton assemblages. Appl Environ Microbiol 56:739-746
Lee SH, Fuhrman JA (1991) Spatial and temporal variation of natural bacterioplankton assemblages studied by total genomic DNA cross-hybridization. Limnol Oceanogr 36: $1277-1287$

Long RA, Azam F (2001) Antagonistic interactions among marine pelagic bacteria. Appl Environ Microbiol 67: 4975-4983

Man D, Wang W, Sabehi G, Aravind L and others (2003) Diversification and spectral tuning in marine proteorhodopsins. EMBO J 22:1725-1731

> Martinez A, Bradley AS, Waldbauer JR, Summons RE, DeLong EF (2007) Proteorhodopsin photosystem gene expression enables photophosphorylation in a heterologous host. Proc Natl Acad Sci USA 104:5590-5595

Massana R, Murray AE, Preston CM, DeLong EF (1997) Vertical distribution and phylogenetic characterization of marine planktonic Archaea in the Santa Barbara Channel. Appl Environ Microbiol 63:50-56

McCarren J, DeLong EF (2007) Proteorhodopsin photosystem gene clusters exhibit co-evolutionary trends and shared ancestry among diverse marine microbial phyla. Environ Microbiol 9:846-858

> Moran MA, Miller WL (2007) Resourceful heterotrophs make the most of light in the coastal ocean. Nat Rev Microbiol 5:792-800

Morris RM, Vergin KL, Cho JC, Rappe MS, Carlson CA, Giovannoni SJ (2005) Temporal and spatial response of bacterioplankton lineages to annual convective overturn at the Bermuda Atlantic Time-series Study site. Limnol Oceanogr 50:1687-1696

Murray AE, Preston CM, Massana R, Taylor LT, Blakis A, Wu K, DeLong EF (1998) Seasonal and spatial variability of bacterial and archaeal assemblages in the coastal waters near Anvers Island, Antarctica. Appl Environ Microbiol 64:2585-2595

>lsen GJ, Lane DL, Giovannoni SJ, Pace NR (1986) Microbial ecology and evolution: a ribosomal RNA approach. Annu Rev Microbiol 40:337-365

> Ouverney CC, Fuhrman JA (2000) Marine planktonic Archaea take up amino acids. Appl Environ Microbiol 66:4829-4833

Pace NR, Stahl DA, Lane DL, Olsen GJ (1986) The analysis of natural microbial populations by rRNA sequences. Adv Microb Ecol 9:1-55

- Pakulski JD, Coffin RB, Kelley CA, Holder SL and others (1996) Iron stimulation of Antarctic bacteria. Nature 383: 133-134

> Pearson A, McNichol AP, Benitez-Nelson BC, Hayes JM, Eglinton TI (2001) Origins of lipid biomarkers in Santa Monica Basin surface sediment: a case study using compound-specific Delta C-14 analysis. Geochim Cosmochim Acta 65:3123-3137

Pomeroy LR, Sheldon JE, Sheldon WM, Peters F (1995) Limits to growth and respiration of bacterioplankton in the Gulf of Mexico. Mar Ecol Prog Ser 117:259-268

> Ruan Q, Dutta D, Schwalbach MS, Steele JA, Fuhrman JA, Sun FZ (2006) Local similarity analysis reveals unique associations among marine bacterioplankton species and environmental factors. Bioinformatics 22: 2532-2538

Rusch DB, Halpern AL, Sutton G, Heidelberg KB and others (2007) The Sorcerer II global ocean sampling expedition: Northwest Atlantic through Eastern Tropical Pacific. PLoS Biol 5:e77

Sabehi G, Loy A, Jung KH, Partha R and others (2005) New insights into metabolic properties of marine bacteria encoding proteorhodopsins. PLoS Biol 3:e273 
Schleper C, Jurgens G, Jonuscheit M (2005) Genomic studies of uncultivated archaea. Nat Rev Microbiol 3:479-488

Schwalbach MS, Brown M, Fuhrman JA (2005) Impact of light on marine bacterioplankton community structure. Aquat Microb Ecol 39:235-245

Spudich JL (1994) Protein-protein interaction converts a proton pump into a sensory receptor. Cell 79:747-750

Spudich JL (2006) The multitalented microbial sensory rhodopsins. Trends Microbiol 14:480-487

Spudich JL, Yang CS, Jung KH, Spudich EN (2000) Retinylidene proteins: structures and functions from archaea to humans. Annu Rev Cell Dev Biol 16:365-392

Stingl U, Desiderio RA, Cho JC, Vergin KL, Giovannoni SJ (2007) The SAR92 clade: an abundant coastal clade of culturable marine bacteria possessing proteorhodopsin. Appl Environ Microbiol 73:2290-2296

Suttle CA (2007) Marine viruses - major players in the global ecosystem. Nat Rev Microbiol 5:801-812

Teira E, Reinthaler T, Pernthaler A, Pernthaler J, Herndl GJ (2004) Combining catalyzed reporter deposition-fluorescence in situ hybridization and microautoradiography to detect substrate utilization by bacteria and archaea in the deep ocean. Appl Environ Microbiol 70:4411-4414

Teira E, Lebaron P, van Aken H, Herndl GJ (2006a) Distri-

Submitted: February 17, 2008; Accepted: May 13, 2008 bution and activity of Bacteria and Archaea in the deep water masses of the North Atlantic. Limnol Oceanogr 51:2131-2144

Teira E, van Aken H, Veth C, Herndl GJ (2006b) Archaeal uptake of enantiomeric amino acids in the meso- and bathypelagic waters of the North Atlantic. Limnol Oceanogr 51:60-69

Thingstad TF, Zweifel UL, Rassoulzadegan F (1998) P limitation of heterotrophic bacteria and phytoplankton in the northwest Mediterranean. Limnol Oceanogr 43:88-94

Venter JC, Remington K, Heidelberg JF, Halpern AL and others (2004) Environmental genome shotgun sequencing of the Sargasso Sea. Science 304:66-74

Woese CR, Fox GE (1977) Phylogenetic structure of the prokaryotic domain: the primary kingdoms. Proc Natl Acad Sci USA 74:5088-5090

Woese CR, Magrum LJ, Fox GE (1978) Archaebacteria. J Mol Evol 11:245-252

Wuchter C, Schouten S, Boschker HTS, Damste JSS (2003) Bicarbonate uptake by marine Crenarchaeota. FEMS Microbiol Lett 219:203-207

Wuchter C, Abbas B, Coolen MJL, Herfort L and others (2006) Archaeal nitrification in the ocean. Proc Natl Acad Sci USA 103:12317-12322

Proofs received from author(s): July 5, 2008 